\title{
Radiation-induced modulation of immunogenic genes in tumor cells is regulated by both histone deacetylases and DNA methyltransferases
}

\author{
ERCAN CACAN, SUSANNA F. GREER and CHARLIE GARNETT-BENSON \\ Department of Biology, Georgia State University, Atlanta, GA 30302, USA
}

Received May 15, 2015; Accepted July 16, 2015

DOI: $10.3892 /$ ijo.2015.3192

\begin{abstract}
Radiation treatment is a pivotal therapy for several cancer types, including colorectal cancer. It has been shown that sublethal doses of radiation modulate gene expression, making tumor cells more susceptible to T-cell-mediated immune attack. We have recently shown that low dose radiation enhances expression of multiple death receptors (Fas, DR4 and DR5) and co-stimulatory molecules (4-1BBL and $\mathrm{OX}-40 \mathrm{~L}$ ) in colorectal cancer (CRC) cells; however, it is unclear how ionizing radiation (IR) enhances expression of these molecules mechanistically. In the present study, we elucidate the molecular mechanisms by which radiation controls expression of these molecules in CRC. Here we report that, enhanced expression of these genes following radiation treatment of CRC cells is due, in part, to changes in DNA methylation and histone acetylation. We observed that radiation (5 Gy) significantly increased histone acetylation at the promoter regions of 4-1BBL, Fas and DR5 but not OX-40L. However, radiation did not induce changes in the global levels of acetylated histone $\mathrm{H} 3$ suggesting specificity of IR-induced changes. Furthermore, evaluation of epigenetic controlling enzymes revealed that IR did not alter overall cellular levels of HDACs (HDAC1, HDAC2 or HDAC3) or DNMTs (DNMT1, DNMT3a, or DNMT3b). Instead, radiation decreased binding of HDAC2 and HDAC3 at the promoter regions of Fas and 4-1BBL, respectively. Radiation also resulted in reduced DNMT1 at both the Fas and 4-1BBL promoter regions but not a control gene. We conclude that single dose radiation can influence the expression of immune response relevant genes in colorectal tumor cells by altering the binding of epigenetic
\end{abstract}

Correspondence to: Dr Charlie Garnett-Benson, Department of Biology, Georgia State University, 161 Jesse Hill Jr. Dr, Atlanta, GA 30302, USA

E-mail: cgarnettbenson@gsu.edu

Key words: radiation, death receptors, co-stimulatory molecules, histone acetylation, DNA methylation enzymes, and modulating histone acetylation, at specific gene promoters.

\section{Introduction}

IR treatment leads to alteration of multiple signaling pathways that control cell survival or cell death (1-4). It is well recognized that ionizing radiation induces DNA damage in human cells and triggers expression of a number of genes (5-7). However, radiation can also alter expression of many genes that are not typically involved in DNA damage and repair pathways $(8,9)$. For example, it has been shown that IR can modulate expression of important immunogenic genes, making tumor cells more susceptible to immune responses (9-12).

Tumor cells escape immune responses by downregulating genes that are essential for effective antitumor immunity (13) such as genes involved in presentation of antigens to $\mathrm{T}$ cells (14), stimulation of T cells (15), and susceptibility to apoptotic signals $(16,17)$. Members of the tumor necrosis factor (TNF) receptor superfamily 4-1BBL/CD137L/TNFSF9 and OX-40L/ CD134L/TNFSF4 are expressed on antigen presenting cells and have been reported to be expressed on tumor cells (9). Interaction between these ligands with their cognate receptors, 4-1BB and OX-40 promotes T cell division, survival, cytokine production and effector cell activity (18-20). Following proper stimulation, cytotoxic T lymphocytes (CTLs) commonly use death receptors such as DR4 (TRAIL-R1), DR5 (TRAIL-R2), and Fas (CD95/Apo-1) to kill tumor cells (21). Interaction between these death receptors with their ligands on antitumor immune cells is essential for driving apoptosis in many types of tumor cells (22). Thus, modulation of these molecules is a promising approach for improving the activity of tumorspecific T cells against resistant cancer cells and for enhancing the efficacy of cancer immunotherapies (23).

A tumor cell undergoes heritable changes in gene function to acquire specific growth advantages (24). Oncogenes may undergo DNA hypomethylation and histone hyperacetylation to promote cell growth and survival $(25,26)$. Conversely, tumor suppressor genes commonly undergo DNA hypermethylation and histone deacetylation to silence these genes and to prevent inhibition of cell growth and survival (27-31). DNA accessibility during transcription is affected by differential packaging of DNA with histone and non-histone proteins into 
chromatin (32). Histone tails are subjected to several modifications that influence the ability of nucleosomes to form stable higher chromatin structures (33). For example, histone acetylation facilitates gene expression whereas histone deacetylases (HDACs) return DNA to a less accessible conformation by removing acetyl groups (34). Cancer cells are known to increase deacetylation and silence genes that would prevent tumor development. Deacetylation is mediated by HDACs which are highly expressed in many cancers, including CRC (35). Class I histone deacetylases (HDAC1, HDAC2 and HDAC3) are recruited into specific transcriptional repression complexes resulting in chromatin condensation and transcriptional silencing (36). In addition to altered acetylation of histones, cancer cells also increase DNA methylation to silence genes whose loss of expression contributes to cancer progression. DNA hypermethylation of $\mathrm{CpG}$ dinucleotides frequently contributes to loss of tumor suppressor genes by accumulating methylation in their promoter regions (37). DNA methylation is carried out by DNA methyltransferases (DNMTs) via catalyzing transfer of methyl groups to cytosine residues in DNA (38). In mammalian cells, three active DNMTs have been identified; DNMT3a and DNMT3b facilitate formation of de novo DNA methylation patterns while DNMT1 is mainly required for maintenance of established patterns of DNA methylation (39). We reported that pharmacological inhibition of HDACs and DNMTs alter expression of OX-40L and 4-1BBL (9). Others showed that expression of death receptors can be influenced by DNA methylation and histone acetylation (40-42); however the molecular details at specific gene promoters remain unknown, as well as how to manipulate their expression in tumors.

Ionizing radiation (IR) is a pivotal treatment modality for several cancers and has been shown to downregulate the expression of class I HDACs (43) and to decrease the activity of DNA methyltransferases $(1,44)$. We have recently shown that sublethal radiation enhances expression of multiple death receptors (10), as well as co-stimulatory molecules (9), in colorectal cancer (CRC) cells. We have also observed increased histone acetylation at the promoter for 4-1BBL (9). These findings suggest that tumor cells surviving radiation treatment could be upregulating transcript expression of immunogenic genes, through modulation of epigenetic enzymes. However, the activity of DNA methylating and histone deacetylating enzymes in the expression of death receptors and co-stimulatory molecules in response to radiation have not been investigated.

These are important questions because epigenetically altered expression of genes can result in changes that are sustained within a tumor cell population, and knowledge about such changes could be further exploited to improve combination cancer immunotherapy strategies. In the present study, we hypothesize that $\mathrm{CRC}$ cells exposed to radiation, at a dose simulating a hypofractionated dose (5 Gy), enhance expression of co-stimulatory molecules and death receptors through modulation of epigenetic enzyme activity at specific genes. We show that enhanced gene expression of several immune-relevant genes following radiation treatment is due, in part, to changes in DNA methylation and histone acetylation. Further, we show that IR increases expression of co-stimulatory molecules and death receptors by decreasing
DNMT1, HDAC2 and HDAC3 levels at the promoter regions of these genes.

\section{Materials and methods}

Reagents and cell lines. 5-Aza-2'-deoxycytidine (5-Aza-dC) and Trichostatin A (TSA) were purchased from Sigma-Aldrich (St. Louis, MO, USA). Antibodies recognizing histone H3 and acetylated histone H3 were from Millipore (Lake Placid, NY, USA). Antibody recognizing HDAC1 were from Santa Cruz. Antibodies recognizing HDAC2, HDAC3, DNMT1, DNMT3a and DNMT3b were from Abcam. Human colorectal carcinoma cell line HCT116 and SW620 cells were purchased from ATCC. All cells were cultured in media designated by ATCC for propagation and maintenance. Cells were incubated at $37^{\circ} \mathrm{C}$ incubator with $5 \% \mathrm{CO}_{2}$ and tested to ensure absence of Mycoplasma.

Irradiation. Tumor cells were irradiated by using an RS-2000 Biological X-ray Irradiator (Rad Source Technology, Suwanee, GA, USA). Cells were irradiated at a dose rate of $2 \mathrm{~Gy} / \mathrm{min}$ for $2.5 \mathrm{~min}$ by setting irradiator voltage and current at $160 \mathrm{kV}$ and $25 \mathrm{~mA}$. During irradiation, the cells were maintained in recommended media and kept on ice. Following irradiation, the culture media was replaced with the fresh media.

Cell surface staining and flow cytometry analysis. HCT116 cells (p53 WT) (45) and SW620 cells (p53 mutant) (46) were irradiated (5 Gy), TSA $(125 \mathrm{nM})$ or 5-AZA-dC $(20 \mu \mathrm{M})$ treated. Cell surface staining of tumor and normal cells were performed using the following primary labeled antibodies; 4-1BBL-PE, OX-40L-PE, Fas-PE, DR4-PE, and DR5-APC and the appropriate isotype matched controls (BioLegend. San Diego, CA, USA). Surface staining was performed in cell staining buffer for $1 \mathrm{~h}$ on ice. Stained cells were acquired on a BD Fortessa flow cytometer (BD Pharmingen, San Diego, CA, USA). Dead cells were excluded from the analysis based on scatter profile. Isotype control staining was $<5 \%$ for all samples analyzed.

Western blot analyses. Cell lysates were electrophoresed through polyacrylamide gels and transferred onto nitrocellulose membranes. Membranes were incubated with antibodies specific for histone H3 (Cell Signaling Technology, Danvers, TX, USA), acetylated histone H3 (Millipore, Lake Placid, NY, USA), HDAC1 (Santa Cruz Biotechnology), HDAC2, HDAC3, DNMT1, DNMT3a and DNMT3b (Abcam, Cambridge, MA, USA), then revealed with secondary horseradish peroxidase (HRP)-conjugated goat anti-rabbit IgG (Santa Cruz Biotechnology) and HRP-conjugated anti-mouse IgG (Promega, Madison, WI, USA).

Chromatin immunoprecipitation (ChIP) assay. ChIP assays were performed as previously described in Cacan et al (30). Briefly, HCT116 cells were irradiated (5 Gy) or TSA (125 nM)treated. Cells were then cross-linked with $1 \%$ formaldehyde and cell nuclei were isolated and concentrated. Cell nuclei were sonicated using a Bioruptor to generate an average of 500-700 bp of sheared DNA. Sonicated lysates were then precleared with salmon-sperm/agarose beads (Upstate) and $5 \%$ of the total lysate was stored as input for normalization. 
Half of the remaining lysate was immunoprecipitated with control antibody, and the other half was immunoprecipitated with $5 \mu \mathrm{g}$ of indicated antibody overnight at $4^{\circ} \mathrm{C}$. Following an additional 2-h immunoprecipitation with salmon-sperm/ agarose beads, all samples were washed and DNA was isolated. Isolated DNA was quantified by real-time PCR on an ABI PR ISM 7900 (Applied Biosystems, Foster City, CA, USA) using the following primers and probe for CD95/Fas: forward, 5'-TCG AGG TCC TCA CCT GAA G-3', reverse, 5'-TGC ACA AAT GGG CAT TCC T-3' and probe, 5'-CCA GCC ACT GCA GGA ACG CC-3'; for DR5: forward, 5'-CCC AAG TGC CTC CCT CAA-3', reverse, 5'-CCG GGC TGT GGT TTG TTT C-3' and probe, 5'-CCC CAA GTT TCG GTG CCT GTC CT-3'; for 4-1BBL: forward, 5'-CAG CAA GAG ACC CAC AGA GAT-3', reverse, 5'-CTC CCT GCT GTC TCT CCA T-3' and probe, 5'-AGA GCG GCA GAG AGG GAG AAC C-3'; for OX-40L: forward, 5'-GGG TTC AAT GTT TAG TTA CA-3', reverse, 5'-GGG TCA CTT GGT AAA GAT A-3' and probe, 5'-GCT GCT ACA TTA ACG GAT GAT GAT T-3'; and for GAPDH: forward, 5'-AAT GAA TGG GCA GCC GTT A-3', reverse, 5'-TAG CCT CGC TCC ACC TGA CT-3' and probe, 5'-CCT GCC GGT GAC TAA CCC TGC GCT CCT-3'. Values generated from real-time PCR reactions were calculated based on standard curves generated, were run in triplicate reactions and were analyzed using the SDS 2.0 program.

Methylation-specific polymerase chain reaction. HCT116 and SW620 cells were plated or irradiated (5Gy) and then incubated for $48 \mathrm{~h}$. Genomic DNA was extracted using the E.Z.N.A. kit according to the manufacturer's protocol. Using the EZ-DNA Methylation-Direct ${ }^{\mathrm{TM}}$ Kit (Zymo Research, Irvine, CA, USA), 750 ng of DNA was bisulfite converted per the manufacturer's instructions. The primers for detection of unmethylated Fas gene were 5'-ATA GGA ATG TTT ATT TGT GTA ATG A-3' (forward) and 5'-CAA AAT CAA AAA CAA ACT CAC AAA-3' (reverse) to generate a 186-bp product. The cycling conditions were $2 \mathrm{~min}$ at $94^{\circ} \mathrm{C}$, followed by 34 cycles of $30 \mathrm{sec}$ at $94^{\circ} \mathrm{C}, 30 \mathrm{sec}$ at $48^{\circ} \mathrm{C}$ and $30 \mathrm{sec}$ at $72^{\circ} \mathrm{C}$. To detect the methylated Fas gene, 5'-GGG ATA GGA ATG TTT ATT TGT GTA AC-3' (forward) and 5'-GAA ATC AAA AAC GAA CTC ACG A-3' (reverse) were used to generate a 188-bp product. The cycling conditions were $2 \mathrm{~min}$ at $94^{\circ} \mathrm{C}$, followed by 34 cycles of $30 \mathrm{sec}$ at $94^{\circ} \mathrm{C}, 30 \mathrm{sec}$ at $52^{\circ} \mathrm{C}$ and $30 \mathrm{sec}$ at $72^{\circ} \mathrm{C}$. The primers for detection of methylated $\beta$-actin gene were 5'-TTT TGC AGG GTT CAC CCT CCT G-3' (forward) and 5'-CGA GCA TCC CCC AAA GTT CAC AA-3' (reverse). The cycling conditions were $2 \mathrm{~min}$ at $94^{\circ} \mathrm{C}$, followed by 34 cycles of $30 \mathrm{sec}$ at $94^{\circ} \mathrm{C}, 30 \mathrm{sec}$ at $58^{\circ} \mathrm{C}$ and $30 \mathrm{sec}$ at $72^{\circ} \mathrm{C}$.

Statistical analyses. Statistical differences between groups were calculated using Student's t-test and calculated at 95\% confidence. Values represent mean \pm SEM of three independent experiments. The $\mathrm{p}$-values $<0.05$ are indicated by one asterisk $(*)$. The p-values $<0.005$ are indicated by two asterisks $(* *)$. The p-values $<0.0005$ are indicated by three asterisks $(* * *)$.

\section{Results}

Surface expression of death receptors and co-stimulatory molecules following treatment with a DNMT inhibitor, HDAC inhibitor or IR in colorectal tumor cells. Epigenetic regulation and suppression of death receptors have been reported in lung, medulloblastoma, and melanoma tumor cell lines $(17,47,48)$, and we have recently reported that expression of OX-40L and 4-1BBL co-stimulatory molecules appear to be sensitive to epigenetic modifications in CRC cells (9). Collectively, these proteins are important in influencing the sensitivity of tumor cells to antitumor immune cells as well as providing positive signals to these responding cells. Interestingly, the expression of these molecules has also been reported to be modulated following irradiation of tumor cells $(9,10)$, however, whether radiation is altering expression of these molecules through specific chromatin remodeling enzymes remains unknown. We first sought to determine if pharmacologic inhibitors of histone deacetylation and DNA methylation could alter the expression of multiple death receptors in colorectal cancer cells in a manner similar to previous observations of co-stimulatory molecules (9). The HDAC inhibitor, TSA, and DNMT inhibitor, 5-Aza-dC, were used to inhibit HDACs and DNMTs activity, respectively. HCT116 cells (p53 WT) treated with $125 \mathrm{nM}$ TSA for 2 days, or with $20 \mu \mathrm{M}$ 5-Aza-dC for 3 days, were compared to cells irradiated with 5 Gy and cell surface protein expression of DR4, DR5, Fas, 4-1BBL and OX-40L was quantified by flow cytometry. Both IR and 5-Aza-dC treatment significantly increased cell surface protein expression of DR4 in HCT116 colorectal carcinoma cells while TSA resulted in a less robust increase that was not significant (Fig. 1A). HCT116 cells uniformly express DR5 (100\% positive) and Fas ( $>98 \%$ positive) on their surface (Fig. 1B and C) and there was no significant decrease in the frequency of cells expressing DR5 and Fas. However, changes in the median fluorescence intensity (MFI) values show a significant change in the expression (density) levels of both DR5 and Fas following radiation, TSA or 5-Aza-dC treatment (Fig. 1, insets B and C). Interestingly, radiation increased both Fas and DR5 MFI more robustly than TSA or 5Aza-dC in these cells. Inhibition of DNA methylation robustly increased expression of all three death receptors with a maximum increase of 3-fold seen in Fas (Fig. 1C). We previously reported that inhibition of HDACs by TSA and treatment with 10 Gy IR could influence expression of co-stimulatory molecules on HCT116 tumor cells. We further evaluated HCT116 cells to determine how significant these differences were and if they occurred at a dose of radiation $<10 \mathrm{~Gy}$. In addition, having previously observed increased expression of co-stimulatory molecule mRNA following inhibition of DNMT using 5-Aza-dC in these cells, we wanted to determine if this treatment could also increase surface expression of the protein. Inhibition of DNMT, HDACs and 5 Gy irradiation significantly increased 41BBL surface expression (Fig. 1D), while only IR significantly increased OX-40L surface expression. While treatment with TSA or 5-Aza-dC appeared to mildly increase OX-40L expression in HCT116 cells, the difference was not significant (Fig. 1E). These data suggest that the contribution of DNA methylation and histone acetylation on the regulation of these two co-stimulatory genes is different.

To confirm that these changes are not limited to HCT116 cells and could occur similarly in another CRC cell line, we evaluated surface expression in treated SW620 (p53 mutated) colorectal cancer cells. SW620 cells were irradiated, treated with TSA or 5-Aza-dC and surface protein expression was 
A

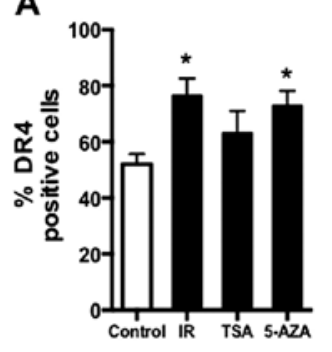

B

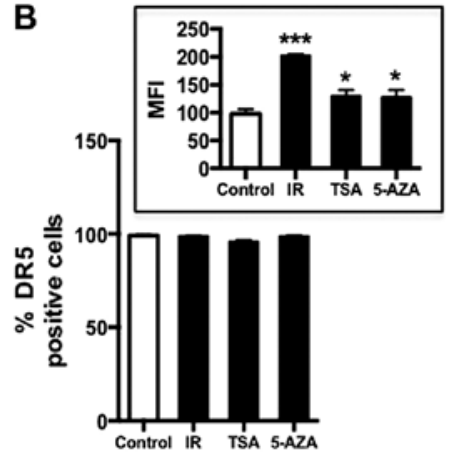

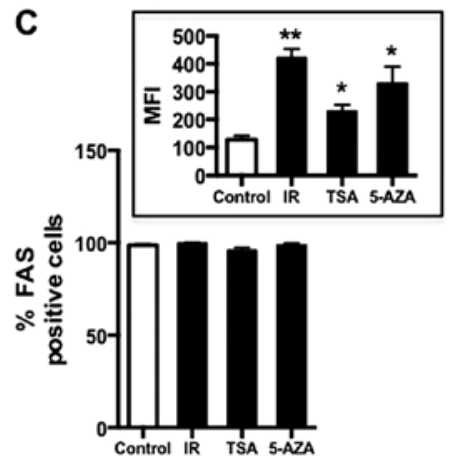
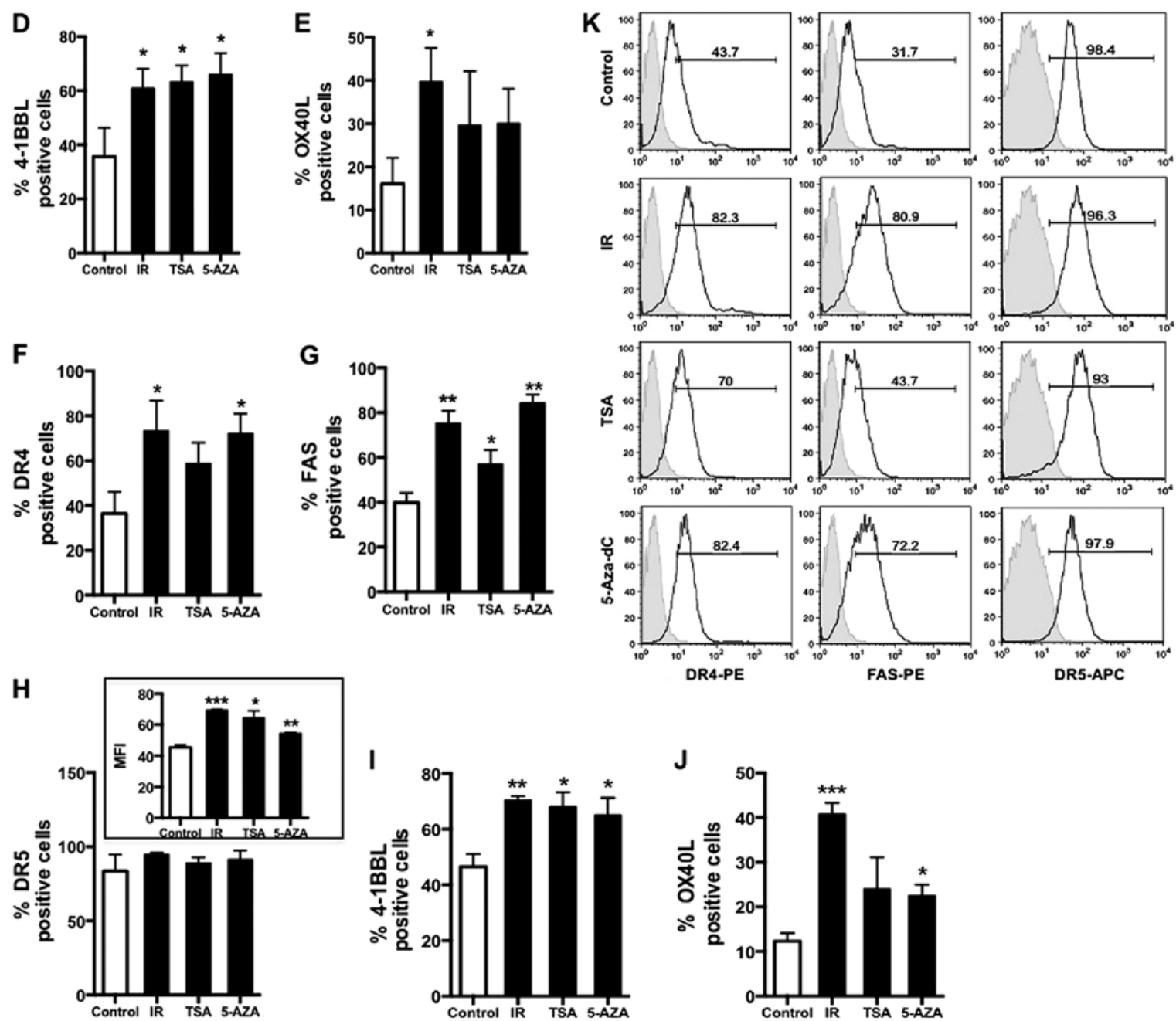

Figure 1. Cell surface expression of death receptors and co-stimulatory molecules are altered by inhibition of chromatin remodeling enzymes in colorectal cancer cells. Surface expression of death receptors and co-stimulatory molecules were evaluated using flow cytometry. Cells were plated and treated with 5-Aza-dC $(20 \mu \mathrm{M})$, TSA $(125 \mathrm{nM})$ or ionizing radiation (5Gy). Adherent cells were harvested and stained with PE-labeled antibody to human DR4, Fas, 4-1BBL and OX-40L or APC-labeled antibody to human DR5 $48 \mathrm{~h}$ after IR or TSA and $72 \mathrm{~h}$ post-5-Aza-dC. Isotype control stained cells were $\leq 5 \%$ positive and analyzed for each treatment group individually. The mean of data is graphed with error bars representing SEM and the p-values are based on three experimental replicates. Experiments were repeated at least three times with similar results. Percent positive values were compared to the level of gene expression see in untreated control samples. ${ }^{*} \mathrm{P}<0.05,{ }^{* * *} \mathrm{P}<0.005$ and $^{* * * *} \mathrm{P}<0.0005$. A) DR4, B) DR5, C) Fas, D) 4-1BBL and E) OX-40L surface expression in HCT116 cells Cells surface expression of F) DR4, G) Fas, H) DR5, I) 4-1BBL and J) OX-40L in SW620 cells. K) Representative FACS plots showing DR4, Fas and DR5 expression following IR, TSA and 5-Aza-dC treatments in SW620 cells.

measured by flow cytometry. Consistent with observations in HCT116 cells, the treatments upregulated the surface expression of DR5, Fas and 4-1BBL most robustly in SW620 cells (Fig. 1G-I). Interestingly, while TSA treatment did appear to increase expression of DR4 and OX-40L the difference was not significant (Fig. 1F and J). Furthermore, we observed a much more robust increase in the expression of OX-40L $48 \mathrm{~h}$ post-IR than previously observed at $24 \mathrm{~h}$ post-IR using a higher dose. In contrast to the significant increase in surface expression of 4-1BBL seen with all three treatments, only IR and 5-Aza-dC induced a significant increase in the expression of OX40L. While the magnitude of 4-1BBL increase was similar between 

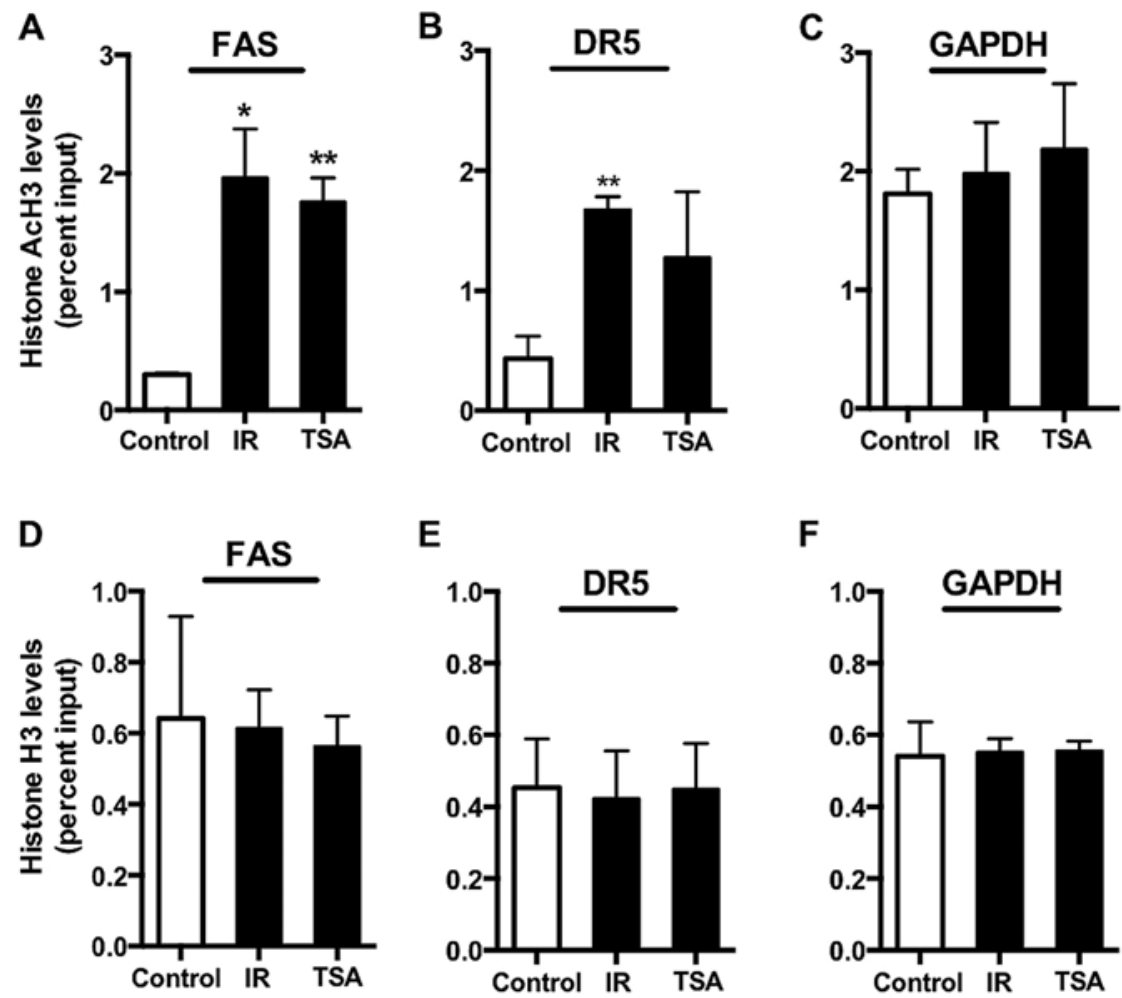

Figure 2. Radiation specifically increases histone acetylation at Fas and DR5 promoters in irradiated CRC cells. ChIP assays were carried out in untreated (0 Gy), irradiated (5 Gy), and TSA-treated (125 nM) HCT116 cells. After 24 h, lysates were immunoprecipitated with control antibody, anti-histone H3 or anti-acetyl histone H3. Associated DNA was isolated and analyzed via real-time PCR using primers spanning the Fas, DR5 and GAPDH promoters. Input values represent $5 \%$ of the total cell lysate. Values represent mean \pm SEM of three independent experiments. ${ }^{*} \mathrm{p}<0.05,{ }^{* *} \mathrm{p}<0.005$. (A-C) Level of Histone H3 acetylation associated with the Fas, DR5 and GAPDH promoters. (D-F) Level of Histone H3 associated with Fas, DR5 and GAPDH promoters.

IR-treated cells and cells treated with the epigenetic drugs, the increase in OX-40L was much lower in drug-treated cells than observed in irradiated cells. Overall, these data indicate that expression of these genes collectively is most consistently increased following exposure to radiation in CRC cell lines. Moreover, we observed that TSA and 5-Aza-dC treatments were also able to significantly enhance expression of DR5, Fas and 4-1BBL across the cell lines.

Histone acetylation at Fas, DR5, 4-1BBL and OX-40L promoters following $I R$. Our data indicate that expression of death receptors and co-stimulatory molecules can be influenced by drugs that inhibit epigenetic activities in the cell, and that radiation also increases expression of these genes in CRC cell lines. We observed a significant increase in the expression of DR5, Fas, 4-1BBL and OX-40L following IR in both colorectal cancer cells. We previously reported that 10 Gy IR increases histone acetylation at the 4-1BBL promoter (9). To explore whether histone modifications also regulate death receptor expression post-IR, we first assessed the levels of histone acetylation at the promoters of DR5 and Fas by ChIP assays in both untreated and irradiated HCT116 cells. TSA inhibits HDACs activity and TSA-treated HCT116 cells were used as a positive control for promoter acetylation. As expected, we observed a robust increase in histone acetylation status following TSA treatment. Histone $\mathrm{H} 3$ acetylation levels significantly increased at both the Fas and DR5 promoters following 5 Gy radiation as compared to untreated control cells (Fig. 2A and B), while we observed similar amounts of total
H3 histone binding at Fas, DR5 promoters (Fig. 2D and E). GAPDH was evaluated in parallel since this gene is stably and constitutively expressed at high levels in most tissues and cells. In contrast, to the increased acetylation we saw at the death receptors promoters, we observed no change in the levels of acetylated histone $\mathrm{H} 3$ at the GAPDH promoter between untreated and irradiated HCT116 cells (Fig. 2C), nor any change in the total $\mathrm{H} 3$ histone binding (Fig. 2F). As GAPDH is gene that is constitutively on and thus in an open, or acetylated, conformation; we also evaluated a gene that would be expected to be closed and remain closed in tumor cells. For this purpose, we looked at the global histone $\mathrm{H} 3$ and acetylated histone $\mathrm{H} 3$ levels at the promoter of CD4 and did not observe any alteration in acetylated histone $\mathrm{H} 3$ levels at this promoter following radiation treatment (data not shown). These data suggest that radiation is specifically causing promoter acetylation of Fas and DR5 and not uniformly across all genes.

We previously reported that 10 Gy IR significantly increased $\mathrm{H} 3$ acetylation at the 4-1BBL promoter in CRC cells and wanted to determine if the same occurred at the promoter of another effector $\mathrm{T}$ cell co-stimulatory molecule. For this we assessed the levels of histone acetylation at the promoter of OX-40L by ChIP assay. Again, TSA-treated HCT116 cells were used as a positive control for promoter acetylation. Since we have already reported enhanced histone acetylation at 4-1BBL promoter following $10 \mathrm{~Gy}$ IR, here we used 4-1BBL promoter acetylation as a positive control but also to determine if 5 Gy IR was sufficient to alter histone acetylation status of this promoter. We found that histone $\mathrm{H} 3$ acetylation levels 
A

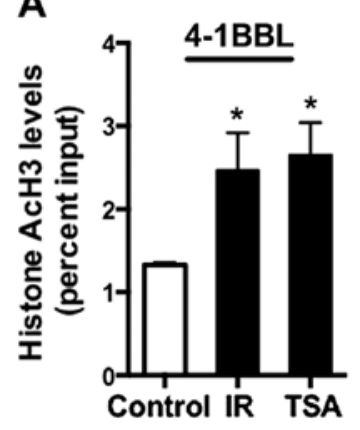

C

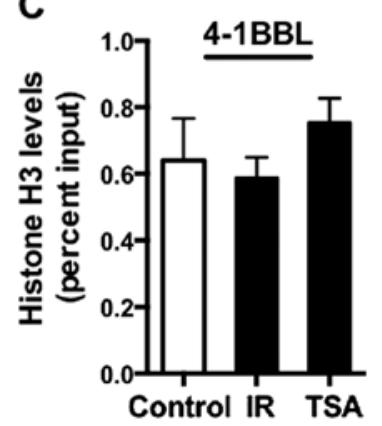

B

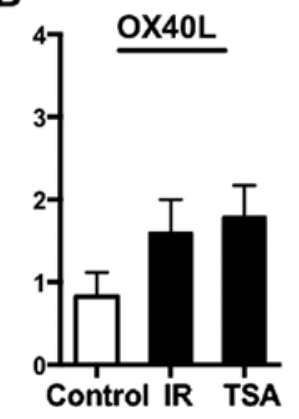

D

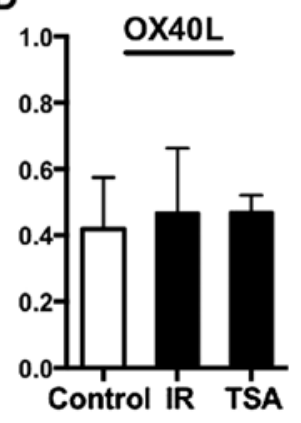

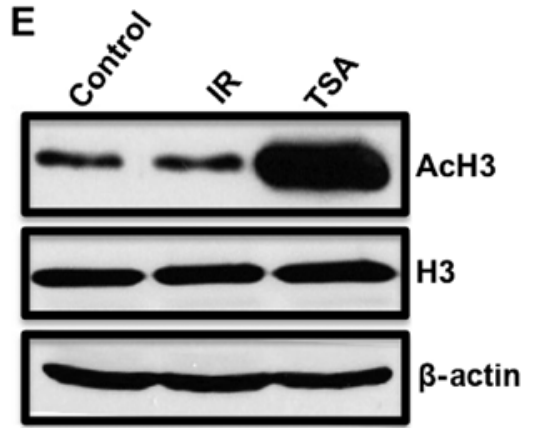

Figure 3. Radiation increases histone acetylation at the 4-1BBL promoter more robustly than at the OX-40L promoter in irradiated CRC cells. ChIP assays were carried out in untreated ( 0 Gy), irradiated ( 5 Gy), and TSA-treated HCT116 cells. Following 24 h of TSA treatment (125 nM), lysates were immunoprecipitated with control antibody, anti-histone $\mathrm{H} 3$ or anti-acetyl histone H3. Associated DNA was isolated and analyzed via real-time PCR using primers spanning the 4-1BBL and OX-40L promoters. Real-time PCR values were normalized to the total amount of promoter DNA added (input). Input values represent 5\% of the total cell lysate. Values represent mean \pm SEM of three independent experiments, ${ }^{*} \mathrm{p}<0.05$. (A-B) Level of Histone H3 acetylation associated with the $4-1 \mathrm{BBL}$ and OX-40L promoters. (C-D) Level of Histone H3 associated with the 4-1BBL and OX-40L promoters. (E) Global cellular protein level of acetylated Histone $\mathrm{H} 3$, histone $\mathrm{H} 3$ and $\beta$-actin.

significantly increased at the 4-1BBL promoter following 5 Gy radiation as compared to untreated control cells (Fig. 3A). Interestingly, we observed a 2-fold increase in histone acetylation level at the OX-40L promoter following 5 Gy IR, however the difference was not significant (Fig. 3B). Thus, we saw no significant change in OX-40L surface expression following TSA treatment in either HCT116 nor SW620 cells (Fig. 1E and $\mathrm{J}$ ), and no significant increase in acetylation at the promoter for this gene. These data suggest that, in contrast to 4-1BBL expression, OX-40L expression is not strongly regulated by histone acetylation. As before, we observed no change in the overall levels of $\mathrm{H} 3$ and total $\mathrm{H} 3$ histone binding was similar at 4-1BBL and OX-40L promoters (Fig. 3C and D), suggesting that the increased acetylation at these promoters is not simply due to increased overall histone $\mathrm{H} 3$ levels in the cells. Overall, our data suggest that radiation increases the expression of some co-stimulatory molecules and death receptors by increasing promoter histone acetylation. This would facilitate transcription initiation by loosening interactions between the histones and DNA; however, the regulation of these genes by histone acetylation shows variability across the genes. We further determined the total cellular histone $\mathrm{H} 3$ and acetylated histone $\mathrm{H} 3$ protein levels in HCT116 cells. TSA-treated cells were used as positive control for histone acetylation and we found that 5 Gy IR did not alter total cellular $\mathrm{H} 3$ or $\mathrm{AcH} 3$ levels in HCT116 cells (Fig. 3G). These data suggest that IR induces histone acetylation in a gene specific manner.
Radiation treatment influences binding of HDAC2 and HDAC3 but not HDAC1 to specific promoters. Histone acetylation is dynamically regulated in cells by the opposing actions of histone acetyltransferases (that add the acetyl functional group to histones), and HDACs (that remove them). We have observed an increase in histone acetylation levels at promoters of co-stimulatory genes and death receptors following radiation treatment of cancer cells. To determine the potential mechanism that could be responsible for the enhancement of histone acetylation following radiation treatment, we sought to evaluate the binding of HDACs to the promoter region of Fas and 4-1BBL since we observed a robust and significant increase in histone acetylation levels at the promoter region of both of these genes. HCT116 cells were irradiated (5 Gy) and ChIP assays were performed to determine binding of class I HDACs to the promoter regions of Fas, 4-1BBL and control gene, GAPDH. We observed that HDAC2 and HDAC3 proteins bind with decreased frequency to the Fas promoter in radiation-treated cells compared to untreated cells (Fig. 4B and $\mathrm{C}$ ), and the change in HDAC2 binding was more significant than that observed with HDAC3. We did not observe any alterations in the binding of HDAC1 to the Fas promoter between control and irradiated cells (Fig. 4A). Similarly, we observed a significant decrease in binding of both HDAC2 and HDAC3 to the 4-1BBL promoter, and no change in binding of HDAC1 to the promoter. These data suggest that HDAC2 and HDAC3 play a role in regulating Fas and 4-1BBL transcription 

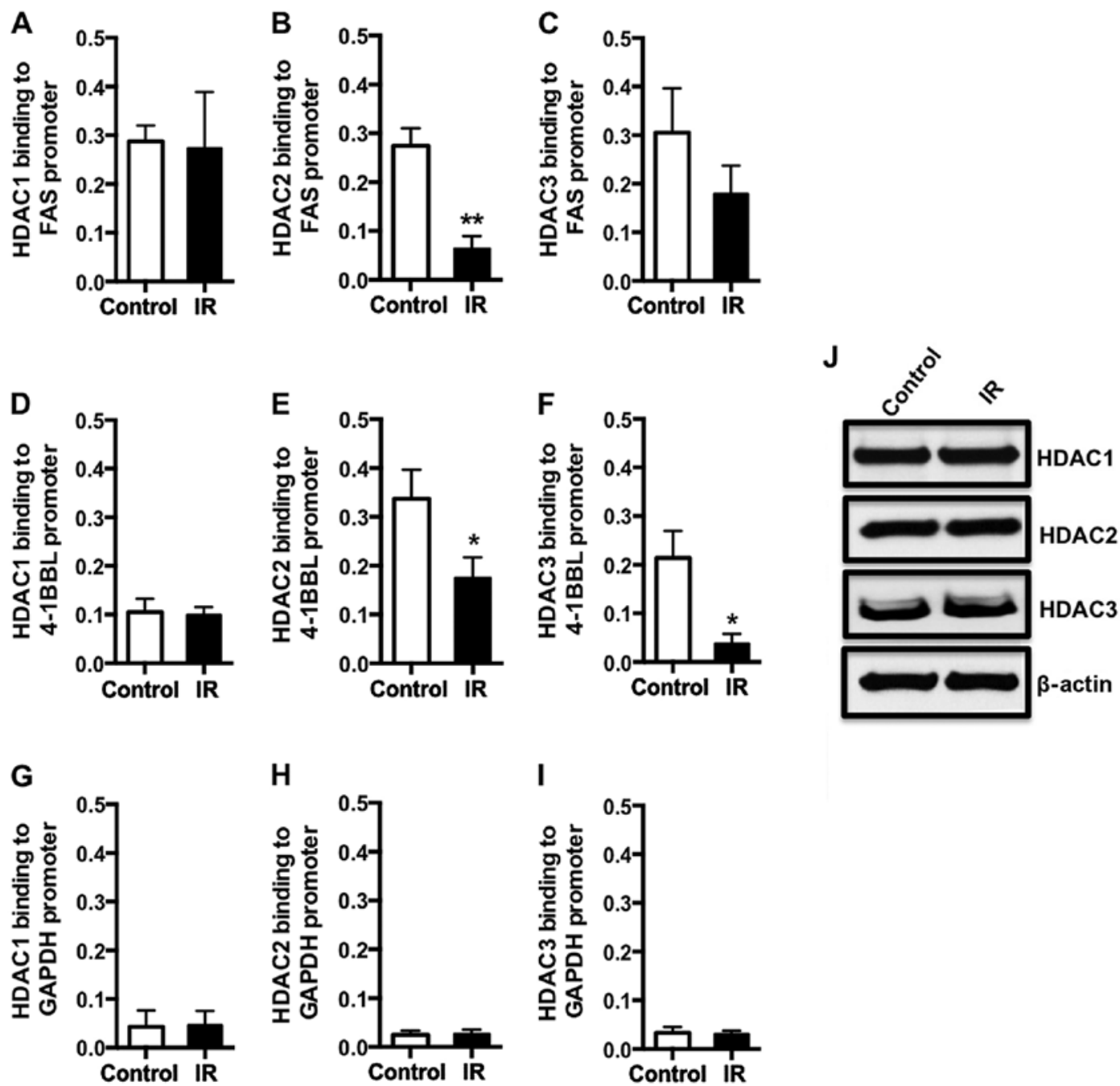

Figure 4. Decreased binding of specific histone deacetylases is detected at the Fas and 4-1BBL promoters in irradiated CRC cells. ChIP assays were carried out in non-irradiated and irradiated (5 Gy) HCT116 cells, and $48 \mathrm{~h}$ post irradiation, lysates were immunoprecipitated with control, HDAC1, HDAC2 or HDAC3 antibody. Associated DNA was isolated and analyzed via RT-PCR using primers spanning the Fas, 4-1BBL and GAPDH promoters. RT-PCR values were normalized to the total amount of promoter DNA added (input). Input values represent $5 \%$ of the total cell lysate. Values represent mean \pm SEM of three independent experiments. ${ }^{*} \mathrm{p}<0.05,{ }^{* * *} \mathrm{p}<0.005$. (A-C) HDAC1, HDAC2 and HDAC3 level associated with the Fas promoters. (D-F) HDAC1, HDAC2 and HDAC3 level associated with the 4-1BBL promoters. (G-I) HDAC1, HDAC2 and HDAC3 level associated with the GAPDH promoters. (J) Global cellular protein levels of class I HDACs and $\beta$-actin.

following radiation of tumor cells. Moreover, radiation mediated decrease in HDAC2 and HDAC3 binding to the Fas and 4-1BBL promoters is gene specific, as there was no significant change in the level of HDAC association with the GAPDH promoter between irradiated and control cells (Fig. 4G-I). To determine if radiation was simply reducing the overall cellular levels of HDAC2 and HDAC3, we performed western blot analysis. HDAC1, HDAC2 and HDAC 3 expression levels were similar in both radiation-treated and untreated cells (Fig. 4J). Together, these data indicate that radiation increases expression of Fas and 4-1BBL molecules, in part, by decreasing HDAC2 and HDAC 3 accumulation at the Fas and 4-1BBL promoters in colorectal cancer cells.

Radiation treatment decreases DNMT1 binding to Fas and 4-1BBL promoters. DNMTs are responsible for methylating DNA and for silencing genes. Recent studies suggest that radiation treatment alters expression of some target genes by changing DNA methylation status of these genes (49). We observed that treatment of CRC cells with 5-Aza-dC or IR increased surface expression of Fas and 4-1BBL in both cell lines evaluated (Fig. 1), suggesting that expression of these molecules is regulated, in part, by DNMTs. However, the role of methylating enzymes in expression of co-stimulatory molecules and death receptors in response to radiation has not been investigated. To determine whether the Fas promoter is methylated in colorectal cancer cells, we utilized methylation specific PCR. We observed that Fas promoter is methylated in HCT116 and SW620 colorectal cancer cells and 5 Gy radiation decreased DNA methylation at Fas promoter in both cell lines (Fig. 5A and B). To determine if radiation treatment causes changes in DNA methylating enzyme status at co-stimulatory and death receptor genes, the human colorectal cell line HCT116 was irradiated and DNMTs binding to the Fas and 4-1BBL promoters was assessed by ChIP assays. We observed a similar binding of DNMT3a and DNMT3b to the Fas promoter following radiation treatment (Fig. 6B and C). However, we detected a significant decrease 
A

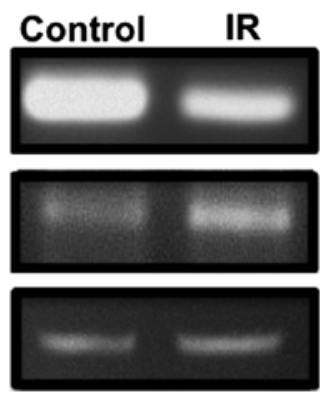

Methylated Fas promoter

Unmethylated Fas promoter

Methylated $\beta$-actin promoter
B

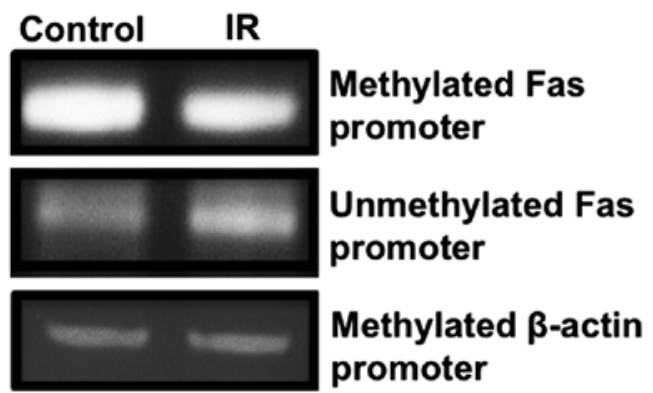

Figure 5. DNA methylation at Fas promoter in untreated and irradiated CRC cells. Methylation specific PCR analysis at the Fas promoter were carried out in non-irradiated and irradiated (5 Gy) CRC cells. Genomic DNA was isolated from cells following radiation. Genomic DNA was bisulfite converted and amplified in PCR with primers specific for non-methylated Fas, methylated Fas, or $\beta$-actin. Promoter methylation of Fas in non-irradiated and irradiated (A) SW620 and (B) HCT116 cells.
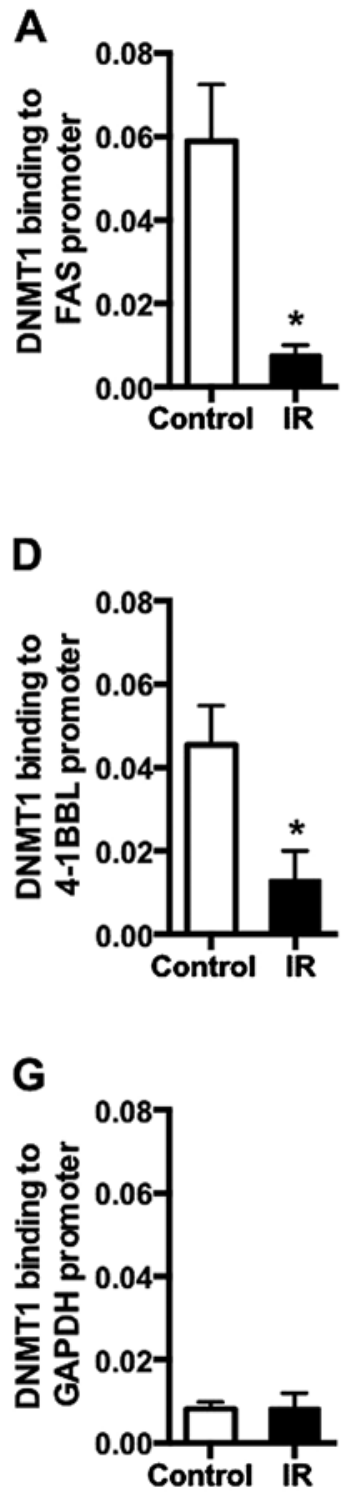
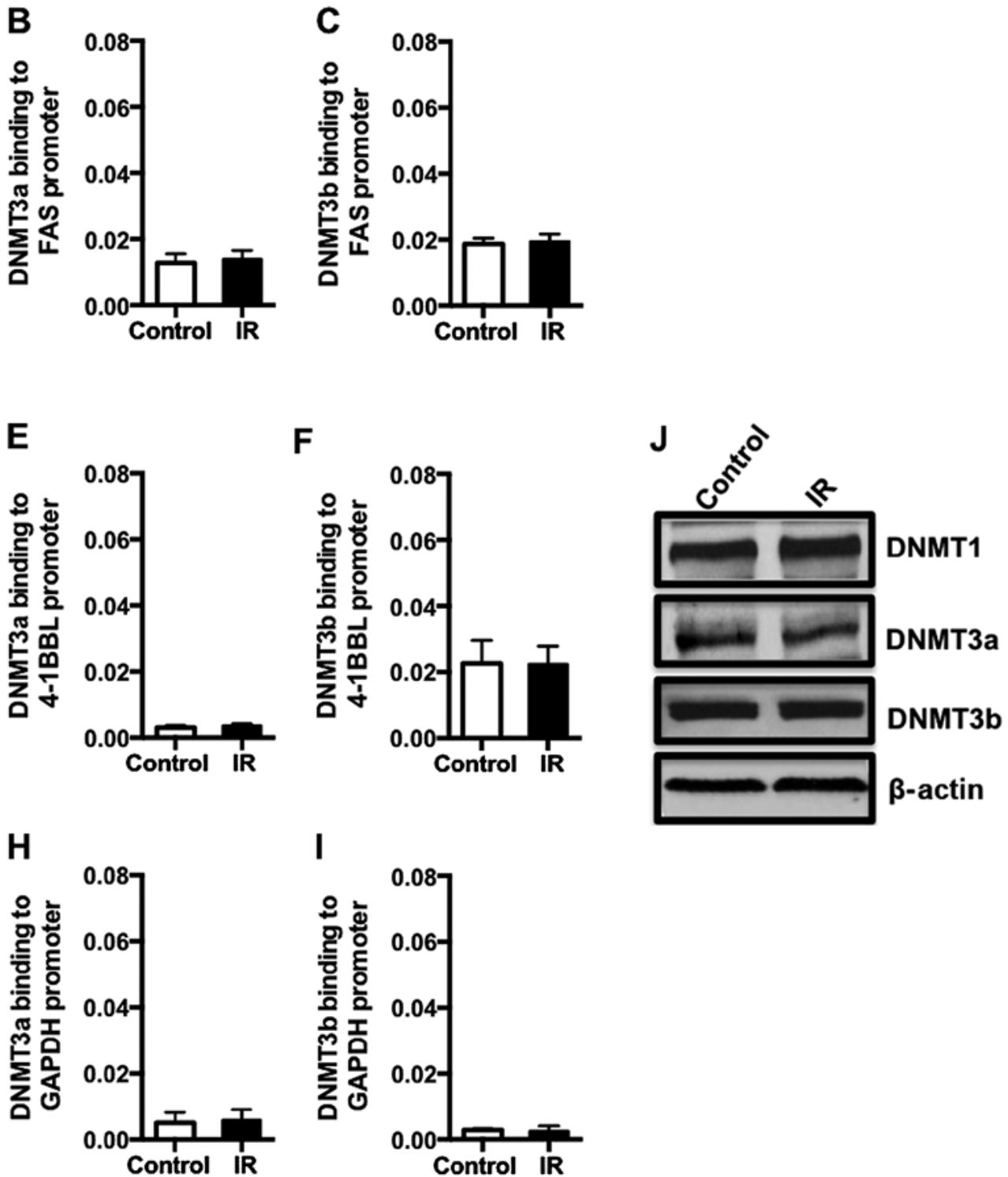
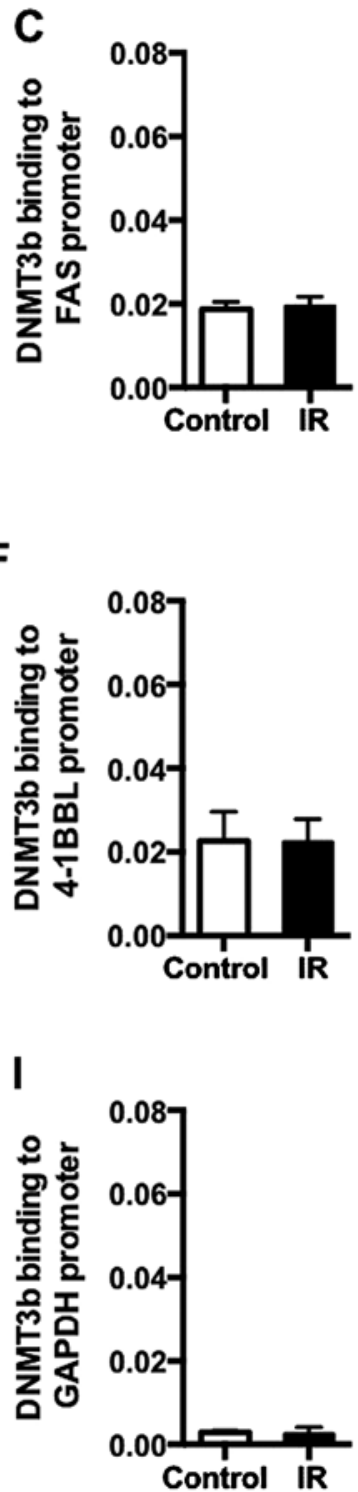

Figure 6. Decreased binding of DNA methyltransferase 1 to Fas and 4-1BBL promoters in irradiated CRC cells. ChIP assays were carried out in nonirradiated and irradiated (5 Gy) HCT116 cells. Lysates were immunoprecipitated with control, DNMT1, DNMT3a or DNMT3b antibody. Associated DNA was isolated and analyzed via real-time PCR using primers spanning the Fas, 4-1BBL and GAPDH promoters. Input values represent 5\% of the total cell lysate. Values represent mean \pm SEM of three independent experiments, ${ }^{*}<<0.05$. (A-C) DNMT1, DNMT3a and DNMT3b level associated with the Fas promoters. (D-F) DNMT1, DNMT3a and DNMT3b level associated with the 4-1BBL promoters. (G-I) DNMT1, DNMT3a and DNMT3b level associated with the GAPDH promoters. (J) Global cellular protein levels of DNMTs and $\beta$-actin. 
in DNMT1 binding to the promoter region of Fas (Fig. 6A). Radiation induced similar changes at the 4-1BBL promoter, and there was no change in the binding of either DNMT3a and DNMT3b (Fig. 6E and F), and a decrease in the binding of DNMT1 (Fig. 6D) following radiation treatment. Conversely, 5 Gy radiation did not cause any alteration in the binding of DNMTs to the promoter of the housekeeping gene, GAPDH (Fig. 6G-I). Further, we determined that overall cellular DNMT1, DNMT3a and DNMT3b levels were unchanged by 5 Gy radiation (Fig. 6J), suggesting that radiation was specifically reducing the binding of DNMT1 to these promoters. These data suggest that DNMT1 also contributes to regulation of Fas and 4-1BBL expression post-IR.

\section{Discussion}

Radiation is clinically used for the treatment various cancers. A better understanding of how radiation modulates the expression of co-stimulatory molecules and death receptors will extend the use of radiation and will be useful in improving cancer immunotherapy strategies used in combination with radiation. We investigated the molecular mechanisms of epigenetic regulation of gene expression in CRC cells in response to IR. We identified that radiation treatment specifically and significantly alters histone acetylation at the promoters of two death receptor genes, Fas and DR5. Further we determined that IR decreases HDAC2, HDAC3 and DNMT1 binding to the promoters of the death receptor Fas and the co-stimulatory molecule 4-1BBL.

DNA methylation and histone acetylation play important roles in chromatin organization and gene regulation in eukaryotic cells. Multiple epigenetic modifications are commonly disrupted during carcinogenesis. Oncogenes undergo hypomethylation on DNA and acetylation and hypermethylation on histones in order to drive enhanced expression $(25,26)$. Conversely, DNA hypermethylation and histone deacetylation commonly occur on tumor suppressor genes to silence expression (27-29). HDACs and DNMT inhibitors induce a potent anticancer response by inhibiting histone deacetylation and DNA hypermethylation to induce expression of pro-apoptotic genes (50-52). Our data indicate that inhibition of DNMTs and HDACs by 5-Aza-dC and TSA induce expression of co-stimulatory molecules and death receptors in colorectal cancer cells. The data presented here further indicate accumulation of DNMT1 and HDAC2/3 at the promoters of such genes suppressing their expression in colorectal cancer cells. Interestingly, not all of the genes analyzed are regulated the same way. For example, expression of DR4 and Fas appear to be dominantly regulated by DNA methylation, based on expression following treatment with epigenetic drugs (Fig. 1), while 4-1BBL seems to be equally regulated by both DNA methylation and histone deacetylation.

Several studies have reported that radiation can alter histone modifications (53-55), however, the direct effect of radiation on histone acetylation and HDACs remains unclear. It has been reported that DR4 expression was downregulated in medulloblastoma tumor samples and increased histone $\mathrm{H} 3$ and $\mathrm{H} 4$ acetylation at the DR4 promoter sensitized medulloblastoma cell lines to TRAIL-induced apoptosis (47). To our knowledge, this is the first report showing the effect of
IR on promoter acetylation of multiple death receptors (Fig. 2) and co-stimulatory molecules (Fig. 3) and alterations in direct binding of class I HDACs to the promoter region of these genes. Our data demonstrate that radiation treatment enhances histone acetylation by decreasing binding of HDAC 2 and HDAC 3 to the Fas and 4-1BBL promoters in HCT116 colorectal cancer cell line (Fig. 4). Interestingly, HDAC1 was found to bind to the Fas promoter in T cells (56), which suggests that different HDACs may play role in regulation of Fas in different cells or tissues. Pollack et al observed an increase at the level of histone $\mathrm{H} 3$ acetylation following UVR exposure at several gene promoters, such as ATF3, COX2 and IL-8, but no increase at the promoter region of the MHC class II gene in $\mathrm{HaCaT}$ cells (54). Consistent with their data, which suggest gene promoter specificity following exposure to radiation, we did not observe changes at the GAPDH promoter acetylation following IR in our current study (Fig. 3). This is further supported by our previous report that $10 \mathrm{~Gy}$ radiation did not alter acetylation of the CIITA promoter in HCT116 cells (9). Yu et al observed that UV irradiation triggers genome-wide histone hyperacetylation at both histone $\mathrm{H} 3$ and $\mathrm{H} 4$ in yeast (53), however we did not observe a global histone hyperacetylation following IR (Fig. 3), which could be due to differences between cell responses to UV radiation versus ionizing radiation or due to differences between yeast and human tumor cells.

Promoter deacetylation and aberrant DNA methylation are two major mechanisms associated with inactivation of tumorsuppressor genes in cancer. Suzuki et al screened over 10,000 genes that are epigenetically silenced in human colorectal cancer (57). They reported that many of the hypermethylated genes have high potential for roles in tumorigenesis. These data further suggest that gene silencing by DNA hypermethylation and histone deacetylation commonly occur on tumor suppressor and proapoptotic genes. Fas downregulation by DNMT1 accumulation has been observed in osteosarcoma and lung carcinoma cell lines (58), and aberrant methylation of Fas promoter was observed in bladder carcinoma $(48,59)$. It has also been reported that DNMT1 silencing upregulates DR5 expression and sensitizes human hepatoma cells to TRAIL-mediated apoptosis (60) and hypermethylation of the DR4 promoter was noted in invasive gastric carcinoma (61). Furthermore, Fas and DR4 suppression was reported in small cell lung carcinoma cell lines and 5-Aza-dC treatment induced expression of these genes (17). Some studies have suggested that radiation can induce global DNA hypomethylation (62), while others observe both DNA hypomethylation and hypermethylation (63). Different biological responses to radiation could be influenced by different doses or tissue types evaluated. We began our investigation by treating cells with 5-Aza-dC to inhibit DNA methylation in order to determine if this would alter expression of some death receptors and co-stimulatory molecules in human CRC cells. We observed increased expression of five of the genes of interest in at least one of the CRC cell lines evaluated (Fig 1). In our studies, we observed a decrease in the binding of DNMT1 to the Fas and 4-1BBL promoters, but no change in global DNA methylation in HCT116 colorectal cancer cells (Fig 6). DNMT1 is required for maintenance of the established patterns of DNA methylation and is highly associated with tumor progression. DNMT1 is recruited to the promoter region of target genes via 
multiple steps and associates with methyl-CpG binding protein (MeCP2) in order to perform maintenance methylation (64). A recent report indicates that radiation treatment decreases level of proteins that function in DNA methylation such as MeCP2 (49). These data suggest that radiation treatment may not directly regulate DNMT1 expression, but may alter DNMT1 recruitment to target gene promoters. Indeed, we observed that IR did not alter global DNMT1 level, but did decrease DNMT1 binding to Fas promoters. If this is a consequence of MeCP2 activity is the subject of future investigation. Interestingly, it has been reported that immunoprecipitated MeCP 2 complexes show DNA methyltransferase activity in hemimethylated DNA (64). In contrast to DNMT1 activity on hemimethylated DNA, DNMT3a and DNMT3b are responsible for de novo methylation of DNA. Thus this could be a reason why we did not observe any alterations in the binding of DNMT3a and DNMT3b to the promoter regions of Fas and 4-1BBL.

DNA methylation and histone deacetylation are often associated with transcriptional repression of gene expression $(65,66)$ and with decreased responsiveness to chemotherapy $(67,68)$. DNA hypermethylation and histone deacetylation contribute to cancer progression and chemoresistance through amplification of master regulators of multiple cell survival pathways (69-73). Clinical trials have demonstrated HDAC inhibitors to be an effective anti-tumor drug therapy (74) and such epigenetic inhibitors have recently shown great therapeutic promise against colorectal cancer (75). Thus, it seems clear that altered gene expression via manipulation of epigenetic control of intrinsic cell death and survival genes in tumors contributes to increased sensitivity to apoptotic signals from subsequent drugs. Here, we report findings suggesting that manipulation of epigenetic regulation of extrinsic cell death genes (i.e. death receptors), as well as immune co-stimulatory molecules, by IR, results in increased sensitivity to attack by immune cells. Indeed, we and others have reported increased killing of tumor cells by $\mathrm{T}$ cells post-IR $(11,12,76)$.

While the ability of radiation to modulate expression of immune relevant genes in tumor cells has been reported by many, detailed investigation into how radiation is altering expression of these genes in tumor cells surviving radiation has been limited. It has recently been reported that microRNAs may regulate expression of some immune relevant genes in non-malignant cells (77), and the data presented here demonstrate that IR can also modulate the binding of epigenetic enzymes to specific promoters. Thus, radiation may alter expression of immune relevant genes in cells that survive treatment via multiple mechanisms. Epigenetic changes could greatly enhance our ability and approach of using IR to enhance immunotherapy strategies as they are retained for quite some time in tumor cell populations (78). Indeed we have observed sustained changes in death receptor expression post-IR (10) and co-stimulatory molecule expression post-IR (unpublished observations). Moreover, because radiation therapy is already a standard of care for many diverse cancers, it may be more amenable than pharmacological epigenetic drugs for use in combination with novel immune-based therapies. Overall, our study suggests that sub-lethal irradiation can immunomodulate tumor cells through epigenetic regulatory mechanisms of specific death receptors and co-stimulatory molecules. Whether radiation treatment will alter expression of other immune relevant genes through these same mechanisms is the subject of further investigation as well as if this regulation occurs similarly in other tissue and cell types.

\section{References}

1. Szumiel I: Ionising radiation-induced oxidative stress, epigenetic changes and genomic instability: The pivotal role of mitochondria. Int J Radiat Biol 91: 1-12, 2015.

2. Agassi AM, Myslicki FA, Shulman JM, Rotterman Y, Dosoretz DE, Fernandez E, Mantz CA and Finkelstein SE: The promise of combining radiation therapy and immunotherapy: Morbidity and toxicity. Future Oncol 10: 2319-2328, 2014.

3. Finkelstein SE, Salenius S, Mantz CA, Shore ND, Fernandez EB, Shulman J, Myslicki FA, Agassi AM, Rotterman Y, DeVries T, et al: Combining immunotherapy and radiation for prostate cancer. Clin Genitourin Cancer 13: 1-9, 2015.

4. Garnett-Benson C, Hodge JW and Gameiro SR: Combination regimens of radiation therapy and therapeutic cancer vaccines: Mechanisms and opportunities. Semin Radiat Oncol 25: 46-53, 2015.

5. Di Leonardo A, Linke SP, Clarkin K and Wahl GM: DNA damage triggers a prolonged p53-dependent G1 arrest and long-term induction of Cipl in normal human fibroblasts. Genes Dev 8: 2540-2551, 1994.

6. d'Adda di Fagagna F, Reaper PM, Clay-Farrace L, Fiegler H, Carr P, Von Zglinicki T, Saretzki G, Carter NP and Jackson SP: A DNA damage checkpoint response in telomere-initiated senescence. Nature 426: 194-198, 2003.

7. Ostling $\mathrm{O}$ and Johanson KJ: Microelectrophoretic study of radiation-induced DNA damages in individual mammalian cells Biochem Biophys Res Commun 123: 291-298, 1984.

8. Tusher VG, Tibshirani R and Chu G: Significance analysis of microarrays applied to the ionizing radiation response. Proc Natl Acad Sci USA 98: 5116-5121, 2001.

9. Kumari A, Cacan E, Greer SF and Garnett-Benson C: Turning $\mathrm{T}$ cells on: Epigenetically enhanced expression of effector T-cell costimulatory molecules on irradiated human tumor cells. J Immunother Cancer 1: 17, 2013.

10. Ifeadi V and Garnett-Benson C: Sublethal irradiation of human colorectal tumor cells imparts enhanced and sustained susceptibility to multiple death receptor signaling pathways. PLoS One 7: e31762, 2012.

11. Gameiro SR, Jammeh ML, Wattenberg MM, Tsang KY, Ferrone S and Hodge JW: Radiation-induced immunogenic modulation of tumor enhances antigen processing and calreticulin exposure, resulting in enhanced T-cell killing. Oncotarget 5: 403-416, 2014.

12. Garnett CT, Palena C, Chakraborty M, Tsang KY, Schlom J and Hodge JW: Sublethal irradiation of human tumor cells modulates phenotype resulting in enhanced killing by cytotoxic T lymphocytes. Cancer Res 64: 7985-7994, 2004.

13. Kim R, Emi M and Tanabe K: Cancer immunoediting from immune surveillance to immune escape. Immunology 121: 1-14, 2007.

14. Bubeník J: MHC class I down-regulation: Tumour escape from immune surveillance (Review)? Int J Oncol 25: 487-491, 2004.

15. Lee H, Kim JH, Yang SY, Kong J, Oh M, Jeong DH, Chung JI, Bae KB, Shin JY, Hong KH, et al: Peripheral blood gene expression of B7 and CD28 family members associated with tumor progression and microscopic lymphovascular invasion in colon cancer patients. J Cancer Res Clin Oncol 136: 1445-1452, 2010.

16. French LE and Tschopp J: Defective death receptor signaling as a cause of tumor immune escape. Semin Cancer Biol 12: 51-55, 2002.

17. Hopkins-Donaldson S, Ziegler A, Kurtz S, Bigosch C, Kandioler D, Ludwig C, Zangemeister-Wittke U and Stahel R: Silencing of death receptor and caspase-8 expression in small cell lung carcinoma cell lines and tumors by DNA methylation. Cell Death Differ 10: 356-364, 2003.

18. Croft M, So T, Duan W and Soroosh P: The significance of OX40 and OX40L to T-cell biology and immune disease. Immunol Rev 229: 173-191, 2009.

19. Tu TH, Kim CS, Nam-Goong IS, Nam CW, Kim YI, Goto T, Kawada T, Park T, Yoon Park JH, Ryoo ZY, et al: 4-1BBL signaling promotes cell proliferation through reprogramming of glucose metabolism in monocytes/macrophages. FEBS J 282: 1468-1480, 2015. 
20. Eun SY, Lee SW, Xu Y and Croft M: 4-1BB ligand signaling to T cells limits T cell activation. J Immunol 194: 134-141, 2015.

21. Guicciardi ME and Gores GJ: Life and death by death receptors. FASEB J 23: 1625-1637, 2009.

22. Koornstra JJ, Kleibeuker JH, van Geelen CM, Rijcken FE, Hollema H, de Vries EG and de Jong S: Expression of TRAIL (TNF-related apoptosis-inducing ligand) and its receptors in normal colonic mucosa, adenomas, and carcinomas. J Pathol 200: 327-335, 2003.

23. Driscoll PC: Structural studies of death receptors. Methods Enzymol 545: 201-242, 2014.

24. Gronbaek K, Hother C and Jones PA: Epigenetic changes in cancer. APMIS 115: 1039-1059, 2007.

25. Jin B, Yao B, Li JL, Fields CR, Delmas AL, Liu C and Robertson KD: DNMT1 and DNMT3B modulate distinct polycomb-mediated histone modifications in colon cancer. Cancer Res 69: 7412-7421, 2009.

26. Müller BM, Jana L, Kasajima A, Lehmann A, Prinzler J, Budczies J, Winzer KJ, Dietel M, Weichert W and Denkert C: Differential expression of histone deacetylases HDAC1, 2 and 3 in human breast cancer--overexpression of HDAC2 and HDAC3 is associated with clinicopathological indicators of disease progression. BMC Cancer 13: 215, 2013.

27. Herman JG and Baylin SB: Gene silencing in cancer in association with promoter hypermethylation. N Engl J Med 349: 2042-2054, 2003.

28. Esteller M: Cancer epigenomics: DNA methylomes and histonemodification maps. Nat Rev Genet 8: 286-298, 2007.

29. Nguyen CT, Gonzales FA and Jones PA: Altered chromatin structure associated with methylation-induced gene silencing in cancer cells: Correlation of accessibility, methylation, MeCP2 binding and acetylation. Nucleic Acids Res 29: 4598-4606, 2001.

30. Cacan E, Ali MW, Boyd NH, Hooks SB and Greer SF: Inhibition of HDAC1 and DNMT1 modulate RGS10 expression and decrease ovarian cancer chemoresistance. PLoS One 9: e87455, 2014.

31. Ali MW, Cacan E, Liu Y, Pierce JY, Creasman WT, Murph MM, Govindarajan R, Eblen ST, Greer SF and Hooks SB: Transcriptional suppression, DNA methylation, and histone deacetylation of the regulator of G-protein signaling 10 (RGS10) gene in ovarian cancer cells. PLoS One 8: e60185, 2013.

32. Ramakrishnan V: Histone structure and the organization of the nucleosome. Annu Rev Biophys Biomol Struct 26: 83-112, 1997.

33. Kouzarides T: Chromatin modifications and their function. Cell 128: 693-705, 2007.

34. Kuo MH and Allis CD: Roles of histone acetyltransferases and deacetylases in gene regulation. BioEssays 20: 615-626, 1998.

35. Stypula-Cyrus Y, Damania D, Kunte DP, Cruz MD, Subramanian H, Roy HK and Backman V: HDAC up-regulation in early colon field carcinogenesis is involved in cell tumorigenicity through regulation of chromatin structure. PLoS One 8: e64600, 2013.

36. Millard CJ, Watson PJ, Celardo I, Gordiyenko Y, Cowley SM, Robinson CV, Fairall L and Schwabe JW: Class I HDACs share a common mechanism of regulation by inositol phosphates. Mol Cell 51: 57-67, 2013.

37. Esteller $\mathrm{M}: \mathrm{CpG}$ island hypermethylation and tumor suppressor genes: A booming present, a brighter future. Oncogene 21: 5427-5440, 2002.

38. Rhee I, Jair KW, Yen RW, Lengauer C, Herman JG, Kinzler KW, Vogelstein B, Baylin SB and Schuebel KE: CpG methylation is maintained in human cancer cells lacking DNMT1. Nature 404: 1003-1007, 2000.

39. Jin B, Li Y and Robertson KD: DNA methylation: Superior or subordinate in the epigenetic hierarchy? Genes Cancer 2: 607-617, 2011.

40. Venza M, Visalli M, Catalano T, Fortunato C, Oteri R, Teti D and Venza I: Impact of DNA methyltransferases on the epigenetic regulation of tumor necrosis factor-related apoptosis-inducing ligand (TRAIL) receptor expression in malignant melanoma. Biochem Biophys Res Commun 441: 743-750, 2013.

41. Maecker HL, Yun Z, Maecker HT and Giaccia AJ: Epigenetic changes in tumor Fas levels determine immune escape and response to therapy. Cancer Cell 2: 139-148, 2002.

42. Jazirehi AR and Arle D: Epigenetic regulation of the TRAIL/ Apo2L apoptotic pathway by histone deacetylase inhibitors: An attractive approach to bypass melanoma immunotherapy resistance. Am J Clin Exp Immunol 2: 55-74, 2013.
43. Mueller S, Yang X, Sottero TL, Gragg A, Prasad G, Polley MY, Weiss WA, Matthay KK, Davidoff AM, DuBois SG, et al: Cooperation of the HDAC inhibitor vorinostat and radiation in metastatic neuroblastoma: Efficacy and underlying mechanisms. Cancer Lett 306: 223-229, 2011.

44. Antwih DA, Gabbara KM, Lancaster WD, Ruden DM and Zielske SP: Radiation-induced epigenetic DNA methylation modification of radiation-response pathways. Epigenetics 8: 839-848, 2013.

45. Kaeser MD, Pebernard S and Iggo RD: Regulation of p53 stability and function in HCT116 colon cancer cells. J Biol Chem 279: 7598-7605, 2004.

46. Rodrigues NR, Rowan A, Smith ME, Kerr IB, Bodmer WF, Gannon JV and Lane DP: p53 mutations in colorectal cancer. Proc Natl Acad Sci USA 87: 7555-7559, 1990.

47. Aguilera DG, Das CM, Sinnappah-Kang ND, Joyce C, Taylor PH, Wen S, Hasselblatt M, Paulus W, Fuller G, Wolff JE, et al: Reactivation of death receptor 4 (DR4) expression sensitizes medulloblastoma cell lines to TRAIL. J Neurooncol 93: 303-318, 2009.

48. Watson CJ, O'Kane H, Maxwell P, Sharaf O, Petak I, Hyland PL, O'Rouke D, McKnight J, Canning $\mathrm{P}$ and Williamson K: Identification of a methylation hotspot in the death receptor Fas/ CD95 in bladder cancer. Int J Oncol 40: 645-654, 2012.

49. Bae JH, Kim JG, Heo K, Yang K, Kim TO and Yi JM: Identification of radiation-induced aberrant hypomethylation in colon cancer. BMC Genomics 16: 56, 2015.

50. Johnstone RW: Histone-deacetylase inhibitors: Novel drugs for the treatment of cancer. Nat Rev Drug Discov 1: 287-299, 2002.

51. Takai N, Desmond JC, Kumagai T, Gui D, Said JW, Whittaker S, Miyakawa I and Koeffler HP: Histone deacetylase inhibitors have a profound antigrowth activity in endometrial cancer cells. Clin Cancer Res 10: 1141-1149, 2004.

52. Lyko F and Brown R: DNA methyltransferase inhibitors and the development of epigenetic cancer therapies. J Natl Cancer Inst 97: 1498-1506, 2005.

53. Yu Y, Teng Y, Liu H, Reed SH and Waters R: UV irradiation stimulates histone acetylation and chromatin remodeling at a repressed yeast locus. Proc Natl Acad Sci USA 102: 8650-8655, 2005.

54. Pollack BP, Sapkota B and Boss JM: Ultraviolet radiationinduced transcription is associated with gene-specific histone acetylation. Photochem Photobiol 85: 652-662, 2009.

55. Ji S, Tian Y, Lu Y, Sun R, Ji J, Zhang L and Duan S: Irradiationinduced hippocampal neurogenesis impairment is associated with epigenetic regulation of bdnf gene transcription. Brain Res 1577: 77-88, 2014.

56. Zimmerman MA, Singh N, Martin PM, Thangaraju M, Ganapathy V, Waller JL, Shi H, Robertson KD, Munn DH and Liu K: Butyrate suppresses colonic inflammation through HDAC1-dependent Fas upregulation and Fas-mediated apoptosis of T cells. Am J Physiol Gastrointest Liver Physiol 302: G1405-G1415, 2012.

57. Suzuki H, Gabrielson E, Chen W, Anbazhagan R, van Engeland M, Weijenberg MP, Herman JG and Baylin SB: A genomic screen for genes upregulated by demethylation and histone deacetylase inhibition in human colorectal cancer. Nature genetics 31: 141-149, 2002.

58. Thaler R, Spitzer S, Karlic H, Berger C, Klaushofer K and Varga F: Ibandronate increases the expression of the pro-apoptotic gene FAS by epigenetic mechanisms in tumor cells. Biochem Pharmacol 85: 173-185, 2013.

59. Li W, Xia D, Wang Y, Li Y, Xue Y, Wu X and Ye Z: Relationship between aberrant methylation of FAS promoter and biological behavior of bladder urothelial carcinoma. J Huazhong Univ Sci Technol Med Sci 31: 794-798, 2011.

60. Kurita S, Higuchi H, Saito Y, Nakamoto N, Takaishi H, Tada S, Saito H, Gores GJ and Hibi T: DNMT1 and DNMT3b silencing sensitizes human hepatoma cells to TRAIL-mediated apoptosis via up-regulation of TRAIL-R2/DR5 and caspase-8. Cancer Sci 101: 1431-1439, 2010.

61. Lee KH, Lim SW, Kim HG, Kim DY, Ryu SY, Joo JK, Kim JC and Lee JH: Lack of death receptor 4 (DR4) expression through gene promoter methylation in gastric carcinoma. Langenbecks Arch Surg 394: 661-670, 2009.

62. Chaudhry MA and Omaruddin RA: Differential DNA methylation alterations in radiation-sensitive and -resistant cells. DNA Cell Biol 31: 908-916, 2012.

63. Aypar U, Morgan WF and Baulch JE: Radiation-induced epigenetic alterations after low and high LET irradiations. Mutat Res 707: 24-33, 2011. 
64. Kimura $\mathrm{H}$ and Shiota K: Methyl-CpG-binding protein, $\mathrm{MeCP} 2$, is a target molecule for maintenance DNA methyltransferase, Dnmt1. J Biol Chem 278: 4806-4812, 2003.

65. Robertson KD: DNA methylation and human disease. Nat Rev Genet 6: 597-610, 2005.

66. Fuks F: DNA methylation and histone modifications: Teaming up to silence genes. Curr Opin Genet Dev 15: 490-495, 2005.

67. Esteller M, Garcia-Foncillas J, Andion E, Goodman SN, Hidalgo OF, Vanaclocha V, Baylin SB and Herman JG: Inactivation of the DNA-repair gene MGMT and the clinical response of gliomas to alkylating agents. N Engl J Med 343: 1350-1354, 2000 .

68. Giacinti L, Vici P and Lopez M: Epigenome: A new target in cancer therapy. Clin Ter 159: 347-360, 2008.

69. $\mathrm{Ng} \mathrm{JM}$ and $\mathrm{Yu} \mathrm{J}$ : Promoter hypermethylation of tumour suppressor genes as potential biomarkers in colorectal cancer. Int J Mol Sci 16: 2472-2496, 2015.

70. Lin PC, Lin JK, Lin CH, Lin HH, Yang SH, Jiang JK, Chen WS, Chou CC, Tsai SF and Chang SC: Clinical relevance of plasma DNA methylation in colorectal cancer patients identified by using a genome-wide high-resolution array. Ann Surg Oncol: Dec 4, 2014 (Epub ahead of print).

71. Gan L, Chen S, Zhong J, Wang X, Lam EK, Liu X, Zhang J, Zhou T, Yu J, Si J, et al: ZIC1 is downregulated through promoter hypermethylation, and functions as a tumor suppressor gene in colorectal cancer. PLoS One 6: e16916, 2011.
72. Vaish V, Khare T, Verma M and Khare S: Epigenetic therapy for colorectal cancer. Methods Mol Biol 1238: 771-782, 2015.

73. Lee SC, Cheong HJ, Kim SJ, Yoon J, Kim HJ, Kim KH, Kim SH, Kim HJ, Bae SB, Kim CK, et al: Low-dose combinations of LBH589 and TRAIL can overcome TRAIL-resistance in colon cancer cell lines. Anticancer Res 31: 3385-3394, 2011.

74. Marks PA, Miller T and Richon VM: Histone deacetylases. Curr Opin Pharmacol 3: 344-351, 2003.

75. Tampakis A, Tampaki EC, Nebiker CA and Kouraklis G: Histone deacetylase inhibitors and colorectal cancer: What is new? Anticancer Agents Med Chem 14: 1220-1227, 2014.

76. Chakraborty M1, Wansley EK, Carrasquillo JA, Yu S, Paik CH, Camphausen K, Becker MD, Goeckeler WF, Schlom J and Hodge JW: The use of chelated radionuclide (samarium153-ethylenediaminetetramethylenephosphonate) to modulate phenotype of tumor cells and enhance T cell-mediated killing. Clin Cancer Res 14: 4241-4249, 2008.

77. Palayoor ST, John-Aryankalayil M, Makinde AY, Falduto MT, Magnuson SR and Coleman CN: Differential expression of stress and immune response pathway transcripts and miRNAs in normal human endothelial cells subjected to fractionated or single-dose radiation. Mol Cancer Res 12: 1002-1015, 2014.

78. Khare S and Verma M: Epigenetics of colon cancer. Methods Mol Biol 863: 177-185, 2012. 